\title{
ADVANCED LAND COVER MAPPING OF TROPICAL PEAT SWAMP ECOSYSTEM USING AIRBORNE DISCRETE RETURN LIDAR
}

\author{
S. Manuri ${ }^{a}$, H. Andersen ${ }^{b}$, C. Brack ${ }^{\text {a }}$, B. Doran ${ }^{a}$ \\ a Fenner School of Environment and Society, The Australian National University, ACT, 2601, Australia \\ ${ }^{b}$ US Forest Service Pacific Northwest Research Station, University of Washington, Seattle, WA 98195, USA
}

\section{Article Info:}

Received: 22 September 2016 in revised form: 23 November 2016 Accepted: 30 November 2016 Available Online: 25 February 2017

\section{Keywords:}

Lidar, FAO forest definition, canopy height, forest and land cover mapping, peat swamp forests

\section{Corresponding Author:}

Solichin Manuri

Fenner School of Environment and Society, The Australian National University, Australia

Email: solichin.solichin@anu.edu.au

\begin{abstract}
The ability to better understand tropical peat ecosystems for restoration and climate change mitigation is often hampered by the lack of availability accurate and detailed data on vegetation cover and hydrologys, which is typically only derived from detailed and high-resolution imaging or field-based measurements. The aims of this study were to explore the potential advantage of airborne discrete-return lidar for mapping of forest cover in peat swamp forests. We used 2.8 pulse. $\mathrm{m}^{-1}$ lidar and the associated 1-m DTM derived from an airborne platform. The lidar dataset fully covered a 120 thousand hectare protection forest in Central Kalimantan. We extracted maximum vegetation heights in 5-m grid resolution to allow detailed mapping of the forest. We followed forest definition from FAO for forest and non-forest classification. We found that lidar was able to capture detail variation of canopy height in highresolution, thus provide more accurate classification. A comparison with existing maps suggested that the lidar-derived vegetation map was more consistent in defining canopy structure of the vegetation, with small standard deviations of the mean height of each class.
\end{abstract}

How to cite (APA 6th Style):

Manuri, S., et al. (2017). Advanced land cover mapping of tropical peat swamp ecosystem using airborne discrete return lidar. Geoplanning: Journal of Geomatics and Planning, 4(1), 1-8. doi:10.14710/geoplanning.4.1.1-8

\section{INTRODUCTION}

The importance of tropical peat swamp forests as carbon sinks and sources are well recognized (Murdiyarso, Hergoualc'h, \& Verchot, 2010). The organic soil of the peat swamp forest, formed by the accumulation of dead vegetation, stores a huge amount of carbon (Jaenicke et al., 2008). On the other hand, there has been a long history of deforestation and forest degradation of peat swamp forests in South East Asia (Miettinen, Shi, \& Liew, 2012). In addition, recurring fires in this region, boosted by El Nino-driven prolonged drought, continues to release carbon into the atmosphere at an alarming rate (Page et al., 2002).

Given the relationships between ecological, hydrological conditions and fire occurrence in tropical peat swamp ecosystems (Wösten et al., 2006), more accurate and detailed baseline information on vegetation cover is needed to support restoration activities designed to mitigate the ecological impact of climate change (Jaenicke et al., 2010). Remote sensing techniques have been deployed for large area mapping of tropical regions, including with high-resolution products (Asner et al., 2012). In peat swamp forest of Central Kalimantan, small-scale illegal logging activities can only be detected using high-resolution (1 -5 meter resolution) optical imagery, due to their low impact to the existing stands (Franke et al., 2012). Airborne light detection and ranging (Lidar) has emerged as a tool to characterize detailed forest structures, providing more accurate ground elevation measurements under canopy and covering a large area (Wulder et al., 2012). 
Lidar has been applied in tropical peat swamp forests for estimating aboveground biomass (Jubanski et al., 2013; Kronseder et al., 2012). However, according to our knowledge, no previous study in tropical peat swamp forests has been carried out for land and forest classification using lidar. Lidar has proven to be an accurate tool for measuring canopy height (Takahashi et al., 2005). Given the advantages of high-resolution airborne lidar in providing highly accurate forest measurements, previous studies have successfully explored the effect of ecological and topographic factors on tree height variations (Saremi et al., 2014) as well as the use of lidar to improve the classification of vegetation structures (Dowling \& Accad, 2003).

According to the FAO definition, "Forest is a land spanning more than 0.5 hectares with trees higher than 5 meters and a canopy cover of more than 10 percent, or trees able to reach these thresholds in situ" (FAO, 2010a). Formally, the forest and land cover maps produced by the government of Indonesia followed correspondingly the definition used by the FAO (FAO, 2010b). Due to technical limitation and the unavailability of high-resolution data, a so-called working definition was used for forest classification and mapping throughout Indonesia (MoEF, 2015).

In this study, we were interested in the utilization of lidar metrics for forest and land cover mapping in a tropical peat swamp ecosystem following the definition of 'forest' by FAO. According to our knowledge, no study has been carried out related to vegetation classification mapping using lidar in tropical peat swamp ecosystem in Indonesia. The aim of this study was to explore the potential advantage of airborne discrete lidar for mapping of forest and land cover in a peat swamp ecosystem. The specific objectives were (1) to classify forest and land cover types based on vegetation heights and (2) to compare with existing forest and land cover maps. This research provides an alternative technique for accurate mapping of peat swamp forest and land cover which is useful for the implementation of land use and spatial planning policies related to restoration of degraded peat land and moratorium oil palm development in high density peat swamp forests.

\section{DATA AND METHODS}

\subsection{Study Site}

Our study site was located at a protection forests, ex Kalimantan Forest Carbon Partnership (KFCP) project area $\left(114^{\circ} 23.5^{\prime}-114^{\circ} 40.3^{\prime} \mathrm{E} ; 1^{\circ} 56.0^{\prime}\right.$ to $\left.2^{\circ} 30.1^{\prime} \mathrm{S}\right)$ in Kapuas District, Central Kalimantan Province, Indonesia (Figure 1). The study site encompasses 119,737 ha of tropical peat swamp ecosystem with a range of degradation levels due to conversion for agriculture, timber extraction and fires.

Figure 1. Study site in peat swamp forest of Central Kalimantan, Indonesia (ESRI and KFCP)

\subsection{Lidar Data}
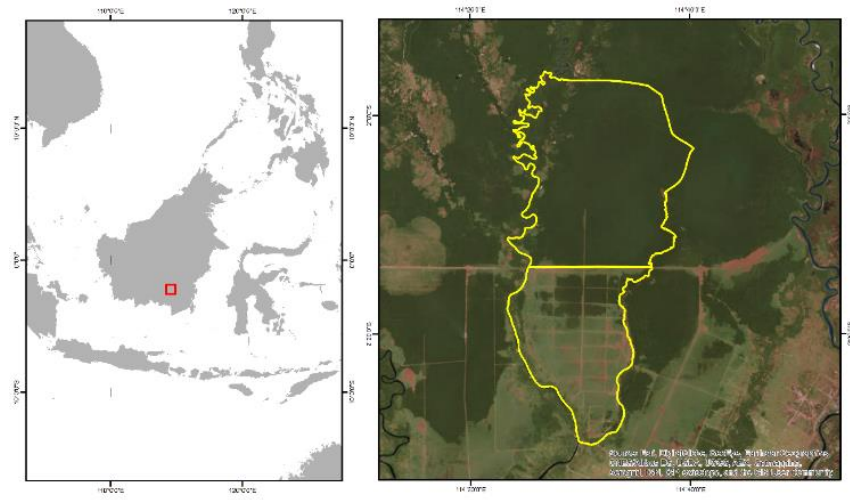

Lidar data sets were provided by the KFCP project. The calculated pulse density was 2.8 pulse. $\mathrm{m}^{-2}$. All datasets were captured using Optech ALTM 3100 and Optech Orion M200 instruments mounted in Pilatus Porter fixed wing aircraft. The vendor provided a 1- meter resolution lidar-derived digital terrain model (DTM) for the KFCP area. The lidar point data was stored in LAS format and split into 1618 tiles. An accuracy assessment carried out after data acquisition found that the vertical accuracy of the lidar data was $0.14 \mathrm{~m}$ (Ballhorn et al., 2014). 


\subsection{Pointcloud Data Processing}

We used FUSION 3.4 LTK Processor to extract lidar metrics from the tiles of pointcloud data and converted into lidar metrics. The 1-m resolution DTM was used for normalizing the terrain effect on the vegetation height. We generated $5-\mathrm{m}$ resolution lidar metrics including the canopy height model in raster format. All relevant lidar metrics were converted to a raster format for further processing.

\subsection{Existing Land and Forest Cover Maps}

Due to the capability in covering a large area, satellite-derived imageries were commonly used for producing land and forest cover maps in Indonesia, such as Landsat and Alos Palsar imageries. Three existing and relevant forest and land cover maps were identified and compiled for the comparison analysis, i.e. produced by Ministry of Forestry (MoF) (Ministry of Forestry, 2012), KFCP (Siegert et al., 2013) and JAXA (Shimada et al., 2014).

The MoF map utilized a mosaic of Landsat imageries from 2010 to 2012. Operators were trained and familiarized with the MoF classification system. The classification was carried out using visual interpretation. KFCP forest and land cover map were clipped from the original file that covered the whole district. The map was produced using object-based classification from a Landsat mosaic. The JAXA map was generated based on Alos Palsar imageries derived from 2010. Only two classes, i.e. forest and non-forest, were produced.

\subsection{Land and Forest Cover Classification}

In this study, we interpreted the vegetation cover based on the canopy height model derived from airborne lidar. Instead of "land use", we used the "land cover" as a basic term for the classification of forest (Lund, 2002). Furthermore, the Land Cover Classification System (LCCS) requires information on vegetation structures, including tree height (Di Gregorio, \& Jansen, 1998). Therefore, for detailed classification of forest and land cover, we further classified the canopy height model into several height classes, i.e. 1, 2, 5, 10, 20 and 30 meters (Table 1). For visualization and comparison purposes, we generalized the classified lidar map (Figure 2). We used ArcGIS 11 Desktop software for the data classification and visualization.

Table 1. Vegetation structures and classification used in this study (modified from Dowling \& Accad (2003))

\begin{tabular}{|c|c|c|c|}
\hline $\begin{array}{l}\text { Vegetation Height } \\
\qquad(\mathrm{m})\end{array}$ & Description & Class & $\begin{array}{l}\text { Generalized } \\
\text { Classes }\end{array}$ \\
\hline $0-1$ & $\begin{array}{l}\text { An open land or bareland, dominated by grasses, ferns and } \\
\text { herbaceous plants. }\end{array}$ & Grassland & Non Forest \\
\hline $1-2$ & $\begin{array}{l}\text { An area covered by shrubs or a mixed between tall grasses } \\
\text { and low woody vegetation, including tree seedlings }\end{array}$ & Shrub & Non Forest \\
\hline $2-5$ & An area covered by tall shrubs and poles & Bush & Non Forest \\
\hline $5-10$ & An area covered with trees with height more than $5 \mathrm{~m}$ & Low forest & Forest \\
\hline $10-20$ & An area covered with trees with height more than $10 \mathrm{~m}$ & Medium tall forest & Forest \\
\hline 20 up & An area covered with trees with height more than $20 \mathrm{~m}$ & Tall forest & Forest \\
\hline
\end{tabular}

We compared the result with the existing forest cover maps and computed the mean and standard deviation of canopy height within the various land and forest cover classes of each map. To assess the significances of the means height difference, we extracted the canopy height values from a set of point samples, which were systematically distributed. As each point represented 1 ha area $(100 \mathrm{~m} \times 100 \mathrm{~m})$, the total number of sample was 119,616 points. We performed the Tukey Honesty Significant Difference test for each class in each map. The significantly different classes were depicted by the different in the mean canopy height. We used JMP 12 for the statistical analysis. 
Figure 2. Flow chart of generating forest cover map using canopy height lidar ESRI (ESRI, 2015).

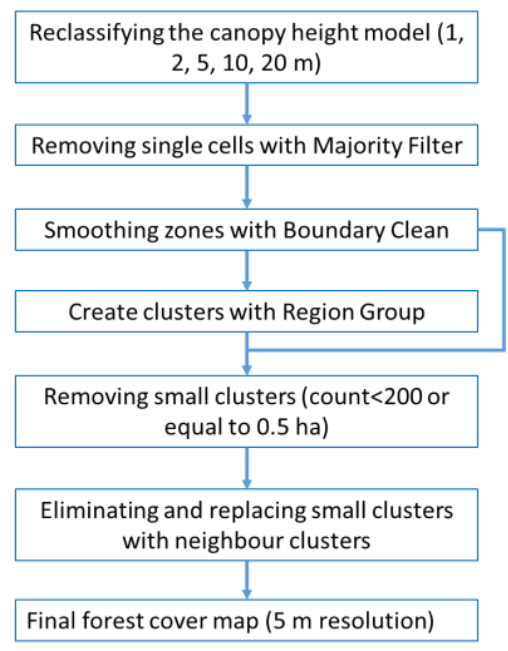

\section{RESULTS AND DISCUSSION}

\subsection{Lidar-derived Land and Forest Cover Map}

A vegetation-height profile showed that detailed variation of the canopy from low vegetation to tall trees can be captured using lidar (Figure 3). Trees along the canals remained after large fires were also detected. This suggested that mapping vegetation structures with high accuracy using lidar was sensible. A forest cover map of the study area was produced using lidar-derived canopy height model, which included forest and non-forest classes with three sub-classes each. More than $65 \%$ of the study site was covered by forest, dominated by medium-tall forest (height between $10-20 \mathrm{~m}$ ) (Table 2). About 35\% of the study site was not forested, which predominantly covered by grasslands and ferns. Open peatlands such as this are the result of repeated fires (Hoscilo et al., 2011; Langner, Miettinen, \& Siegert, 2007).

Figure 3. Canopy height profile depicted detail variation of vegetation height

(Own Analysis, 2016)

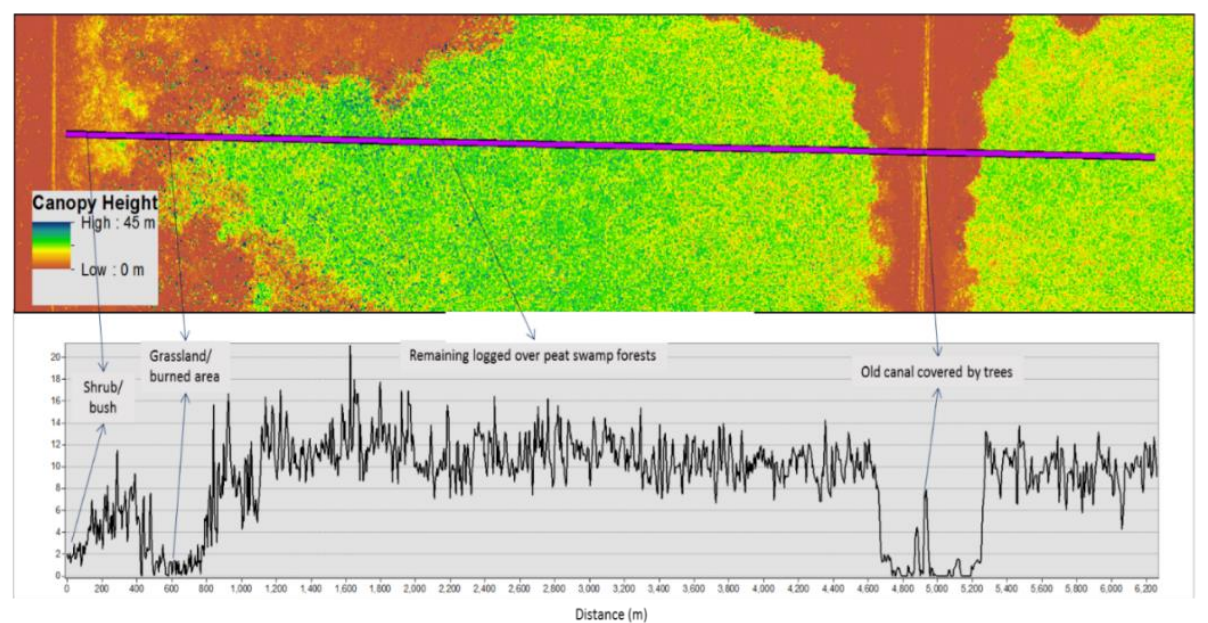

Table 2. Summary of vegetation classes covering study site (Own Analysis, 2016)

\begin{tabular}{|c|c|c|c|c|}
\hline Vegetation Classes & Size (ha) & Size (\%) & Ha forest & $\%$ Forest and Non-Forest \\
\hline Grassland & 25,162 & 21.0 & 41,413 & 34.6 \\
\hline Shrub & 5,923 & 5.0 & & \\
\hline Bush & 10,328 & 8.6 & & \\
\hline Low Forest & 11,164 & 9.3 & 78,235 & 65.4 \\
\hline Medium Tall Forest & 67,054 & 56.0 & & \\
\hline Tall Forest & 17 & 0.0 & & \\
\hline
\end{tabular}




\subsection{Comparison with Existing Land and Forest Cover Maps}

We carried out a mean canopy height comparison between the lidar-derived map and the existing maps. We computed the mean canopy height and its standard deviation of the classes of each map. Most of the secondary forest classes from the existing maps were in agreement with our medium tall forest class, which had canopy height ranging between $10 \mathrm{~m}-20 \mathrm{~m}$ and mean canopy height about 13 meters (Figure 4). However, none of the forest classes of existing maps were equivalent to our low forest classes, which had height range between $5 \mathrm{~m}-10 \mathrm{~m}$. The KFCP bush/shrub/regrowth class was equivalent to our low forest class, with the mean canopy height of $7.5 \mathrm{~m}$. The MoF bush/shrub class had lower mean canopy height $(4.8 \mathrm{~m})$ than the KFCP bush/shrub class, although it was extremely closed to the threshold of the FAO forest definition $(5 \mathrm{~m})$. None of the class in the existing maps represented the high canopy forests similar to our tall forest class. Surprisingly, the KFCP primary forest class had an even lower mean height than its secondary forest. In contrast, the MoF settlement class had the mean height of $9.3 \mathrm{~m}$, much higher than the lowest height threshold of FAO forest definition. Furthermore, most of the KFCP and MOF nonforest classes had insignificant differences in mean heights (Figure 4).

Figure 4. Mean canopy height of vegetation classes and their standard deviation. Different letters depicted significant differences of the mean values within each map (Tukey's HSD test).

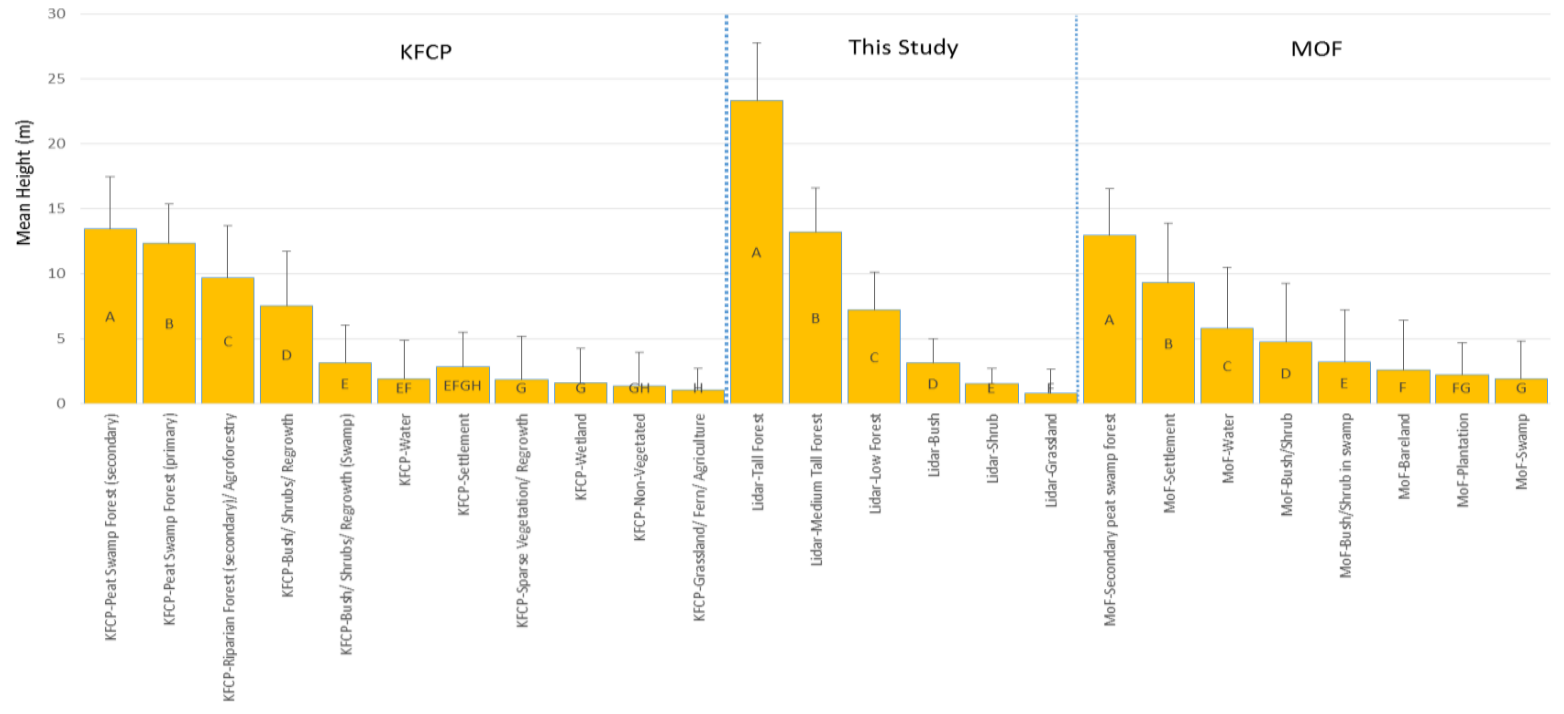

Figure 5 illustrated the significantly-different mean heights between forest and non-forest classes of each map. This suggested that the existing forest/non-forest maps had better accuracy in defining the classes than the detailed forest and land classification maps. Regarding size of the area, the Jaxa forest/non-forest map had better agreement with our result. However, regarding the spatial distribution of the forests, we found that the KFCP forest/non-forest map was in better agreement with the lidar-derived forest/nonforest map (Figure 6).

Figure 5. Mean canopy height of each forest and non-forest classes and their standard deviation

(Own Analysis, 2016)

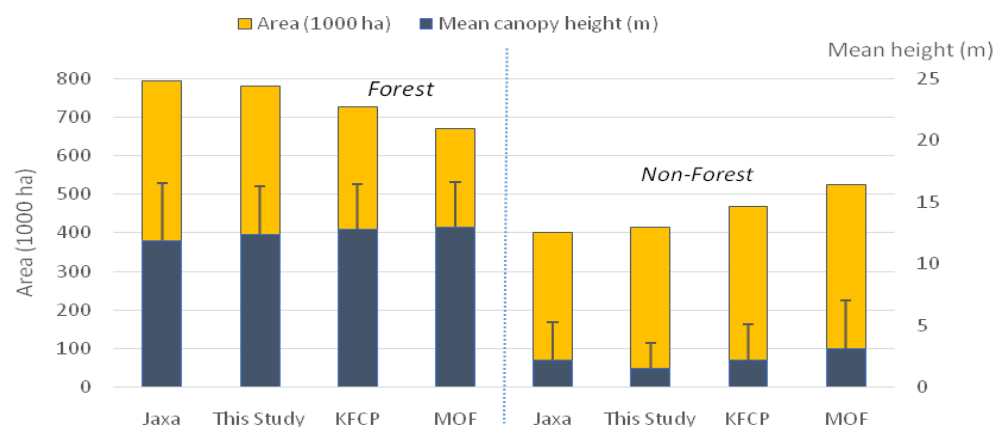


Figure 6. Forest and land cover maps of the study area, derived by (a) this study, (b) Shimada et al. (2014) (c) Ministry of Forestry (2012) and (d) Siegert et al. (2013)
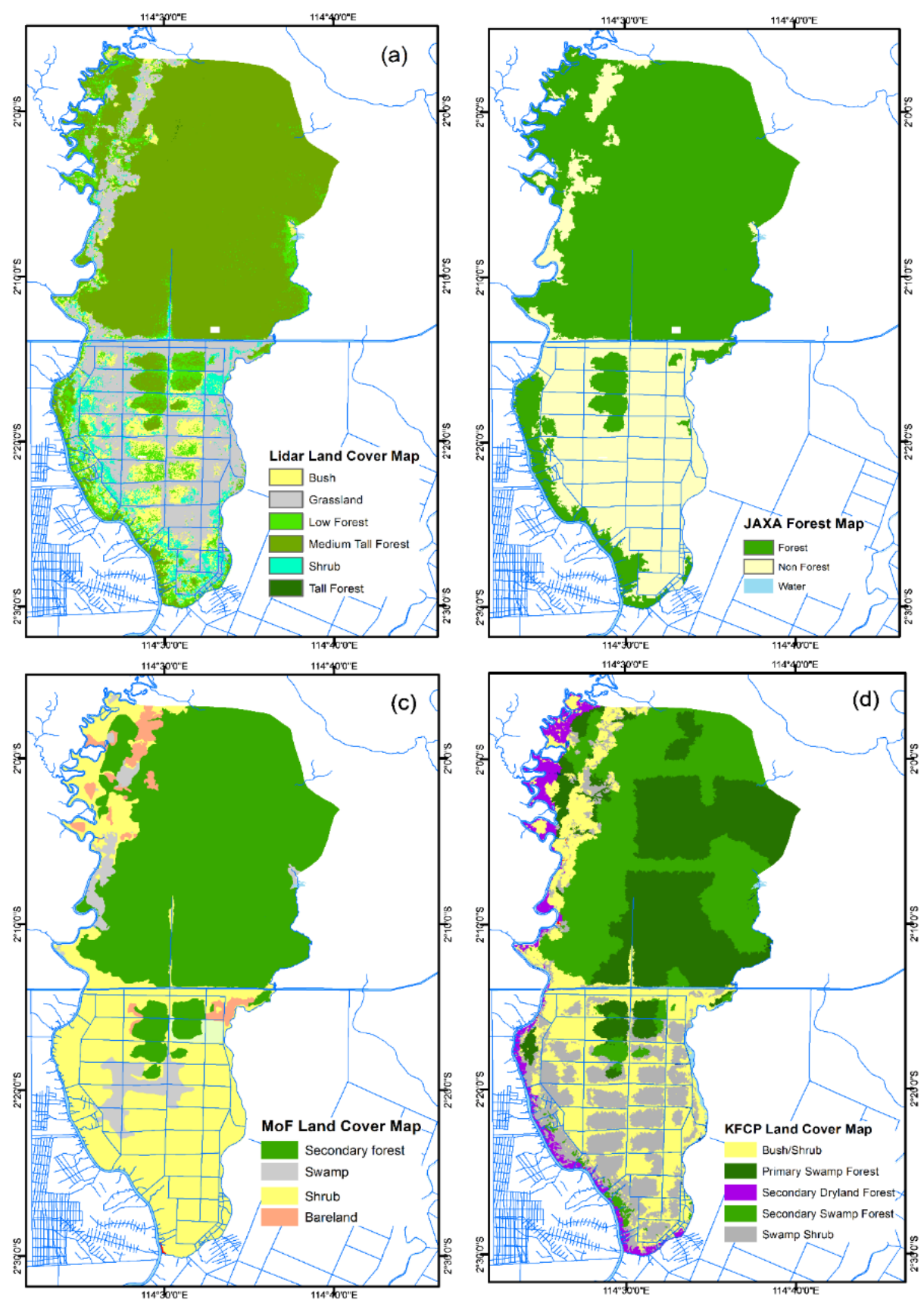

Mapping of vegetation structures with high accuracy using lidar is sensible. This approach will support more detailed and accurate vegetation mapping, and in particular, will allow the use of a classification system based on physiognomy and canopy height structures (Ellenberg \& Mueller-Dombois, 1966; Woodwell, 1984). On the other hand, existing forest and land cover maps, which relied on optical and active sensor imageries, tend to be inconsistent in identifying the spatial distribution of detail forest and land classes, due to their lower resolution. However, high-resolution optical imagery may also have a similar limitation (Nagendra \& Rocchini, 2008).

Compared to the aerial photos, lidar offers great advantages in accuracy and fully automated digital processing in vegetation mapping (Dowling \& Accad, 2003). Lidar also advanced in the identification of inundated wetland areas using the pulse intensity (Lang \& McCarty, 2009). Floristic classification remains a practical limitation in tropical vegetation mapping using lidar, which is also a common problem with other optical sensors. To overcome this limitation, several studies successfully integrated lidar with hyperspectral 
sensor for species identification in temperate regions (Holmgren, Persson, \& Söderman, 2008; Jones, Coops, \& Sharma, 2010), although it was less successful in mangrove vegetation (Hirano, Madden, \& Welch, 2003) and highly diverse tropical forests (Clark et al., 2011).

\section{CONCLUSION}

The goal of this study was to explore the potential advantage of airborne discrete lidar for vegetation cover mapping in peat swamp forests. Lidar was able to capture detail variation of canopy height in highresolution, thus provide more accurate classification. A comparison with existing maps, suggested that the lidar-derived vegetation map was more consistent in defining canopy structure of the vegetation.

\section{ACKNOWLEDGMENTS}

The study was supported by the Silva Carbon Program, USA. The lidar dataset was provided by the KFCP-AusAid project and the Indonesian Ministry of Environment and Forestry. Solichin Manuri was supported by Australian Award Scholarship.

\section{REFERENCES}

Asner, G. P., et al. (2012). High-resolution mapping of forest carbon stocks in the Colombian Amazon. Biogeosciences, 9(7), 2683-2696. [CrossRef]

Ballhorn, U., et al. (2014). LiDAR Survey of the Kalimantan Forests and Climate Partnership (KFCP) Project Site and EMRP Area in Central Kalimantan, Indonesia.

Clark, M. L., et al. (2011). Estimation of tropical rain forest aboveground biomass with small-footprint lidar and hyperspectral sensors. Remote Sensing of Environment, 115(11), 2931-2942. [CrossRef]

Di Gregorio, A., \& Jansen, L. J. M. (1998). Land Cover Classification System (LCCS): classification concepts and user manual. $F A O$, Rome.

Dowling, R., \& Accad, A. (2003). Vegetation classification of the riparian zone along the Brisbane River, Queensland, Australia, using light detection and ranging (lidar) data and forward looking digital video. Canadian Journal of Remote Sensing, 29(5), 556-563. [CrossRef]

Ellenberg, H., \& Mueller-Dombois, D. (1966). Tentative physiognomic-ecological classification of plant formations of the earth. Instituts der Eidg. Techn. Hochshule Stiftung Rb̈er.

ESRI. (2015). ArcGIS for Desktop: An overview of the generalization toolset. Retrieved from http://pro.arcgis.com/en/pro-app/tool-reference/data-management/an-overview-of-thegeneralization-toolset.htm

FAO. (2010a). Global Forest Resources Assessment 2010. Rome: Food and Agriculture Organization of the United Nations Forestry. Retrieved from http://www.fao.org/docrep/013/i1757e/i1757e.pdf

FAO. (2010b). Global Forest Resources Assessment 2010: Country Report. Food and Agriculture Organization of the United Nations Forestry. Retrieved from http://www.fao.org/docrep/013/al531E/al531E.pdf

Franke, J., et al. (2012). Monitoring Fire and Selective Logging Activities in Tropical Peat Swamp Forests. IEEE Journal of Selected Topics in Applied Earth Observations and Remote Sensing, 5(6), 1811-1820. [CrossRef]

Hirano, A., Madden, M., \& Welch, R. (2003). Hyperspectral image data for mapping wetland vegetation. Wetlands, 23(2), 436-448. [CrossRef]

Holmgren, J., Persson, Å., \& Söderman, U. (2008). Species identification of individual trees by combining high resolution LiDAR data with multi-spectral images. International Journal of Remote Sensing, 29(5), 1537-1552. [CrossRef]

Hoscilo, A., et al. (2011). Effect of repeated fires on land-cover change on peatland in southern Central Kalimantan, Indonesia, from 1973 to 2005. International Journal of Wildland Fire, 20(4), 578. [CrossRef]

Jaenicke, J., et al. (2008). Determination of the amount of carbon stored in Indonesian peatlands. Geoderma, 147(3-4), 151-158. [CrossRef]

Jaenicke, J., et al. (2010). Planning hydrological restoration of peatlands in Indonesia to mitigate carbon dioxide emissions. Mitigation and Adaptation Strategies for Global Change, 15(3), 223-239. [CrossRef] 
Jones, T. G., Coops, N. C., \& Sharma, T. (2010). Assessing the utility of airborne hyperspectral and LiDAR data for species distribution mapping in the coastal Pacific Northwest, Canada. Remote Sensing of Environment, 114(12), 2841-2852. [CrossRef]

Jubanski, J., et al. (2013). Detection of large above-ground biomass variability in lowland forest ecosystems by airborne LiDAR. Biogeosciences, 10(6), 3917-3930. [CrossRef]

Kronseder, K., et al. (2012). Above ground biomass estimation across forest types at different degradation levels in Central Kalimantan using LiDAR data. International Journal of Applied Earth Observation and Geoinformation, 18, 37-48. [CrossRef]

Lang, M. W., \& McCarty, G. W. (2009). Lidar intensity for improved detection of inundation below the forest canopy. Wetlands, 29(4), 1166-1178. [CrossRef]

Langner, A., Miettinen, J., \& Siegert, F. (2007). Land cover change 2002-2005 in Borneo and the role of fire derived from MODIS imagery. Global Change Biology, 13(11), 2329-2340. [CrossRef]

Lund, H. G. (2002). When is a Forest Not a Forest? Journal of Forestry, 100(8), 21-28.

Miettinen, J., Shi, C., \& Liew, S. C. (2012). Two decades of destruction in Southeast Asia's peat swamp forests. Frontiers in Ecology and the Environment, 10(3), 124-128. [CrossRef]

Ministry of Forestry. (2012). Improvement of Land Cover Change Estimate of Indonesia for Year 2011 (In Indonesian).

MoEF. (2015). National Forest Reference Emission Level for Deforestation and Forest Degradation: In the Context of Decision 1/CP.16 para 70 UNFCCC (Encourages developing country Parties to contribute to mitigation actions in the forest sector).

Murdiyarso, D., Hergoualc'h, K., \& Verchot, L. V. (2010). Opportunities for reducing greenhouse gas emissions in tropical peatlands. Proceedings of the National Academy of Sciences, 107(46), 1965519660. [CrossRef]

Nagendra, H., \& Rocchini, D. (2008). High resolution satellite imagery for tropical biodiversity studies: the devil is in the detail. Biodiversity and Conservation, 17(14), 3431-3442. [CrossRef]

Page, S. E., et al. (2002). The amount of carbon released from peat and forest fires in Indonesia during 1997. Nature, 420(6911), 61-65. [CrossRef]

Saremi, H., et al. (2014). Airborne LiDAR derived canopy height model reveals a significant difference in radiata pine (Pinus radiata D. Don) heights based on slope and aspect of sites. Trees, 28(3), 733-744. [CrossRef]

Shimada, M., et al. (2014). New global forest/non-forest maps from ALOS PALSAR data (2007-2010). Remote Sensing of Environment, 155, 13-31. [CrossRef]

Siegert, F., et al. (2013). Historical Land Cover Classification and Land Cover Change in the Kalimantan Forests and Climate Partnership (KFCP) site and the Kapuas Hulu District.

Takahashi, T., et al. (2005). Estimating individual tree heights of sugi (Cryptomeria japonica D. Don) plantations in mountainous areas using small-footprint airborne LiDAR. Journal of Forest Research, 10(2), 135-142. [CrossRef]

Woodwell, G. M. (1984). The Role of terrestrial vegetation in the global carbon cycle: measurement by remote sensing. Published on behalf of the Scientific Committee on Problems of the Environment (SCOPE) of the International Council of Scientific Unions (ICSU) by Wiley. Retrieved from https://books.google.co.id/books?id=AkNRAAAAMAAJ

Wösten, J. H. M., et al. (2006). Interrelationships between Hydrology and Ecology in Fire Degraded Tropical Peat Swamp Forests. International Journal of Water Resources Development, 22(1), 157-174. [CrossRef]

Wulder, M. A., et al. (2012). Lidar sampling for large-area forest characterization: A review. Remote Sensing of Environment, 121, 196-209. [CrossRef] 